Lungs were studded with miliary tubercle, increasing in quantity from apex to base; on section the tissue seemed exsanguine, of a grayish color, dotted with the black tubercle and filled with numerous cavities, varying in size from a pin to a small orange, containing offensive pus, with the exception of a small portion at base of each lung which was highly congested, with lubercle throughout its substance. All the smaller bronchial branches were obliterated by the tubercular deposit in the surrounding portion of the tissue. Fibrinous bands were found between the lobes and the larger cavities were lined by a similar membrane.

Larynx.-The upper part of posterior portion of the thyroid, the arytenoid, the epiglottis, and the ligaments and attachments corresponding to these, with the vocal cords, were destroyed by ulceration.

Abdominal viscera not examined, and cranium not opened, as it was deemed unnecessary.

\section{NOTES ON TWENTY-SEVEN CASES OF DIPHTHERIA,}

OCCURRING BETWEEN JULY 1, 1888, AND JANUARY 1, 1889.

Read before the Section for Clinical Medicine, Pathology and Hygiene, of the Suffolk District Medical Society, January 19, 1889.

BY HENRY JACKSON, M.D.,

of Bostox.

From July I, I 888 , to January I, I 889 , I treated twenty-seven cases of diphtheria out of 1,03 I cases of all kinds, seen in the second district of the Boston Dispensary, situated on the West side of Hanover street. Of these cases, five died; four of septicæmia, one of laryngeal obstruction.

Five cases were very mild; two were not confined to the bed.

In most of the cases the membrane was confined to the uvula and pillars of the pharynx. In these cases a large part of the roof of the mouth and lips was covered with membrane. Fifteen cases occurred in houses where the sanitary condition was bad. Ten case where the sanitary condition was apparently good. Two cases in a house that seems to be in good condition, and yet one where I have found much sickness in the last two years, notably diphtheria last winter.

Where there were several children in a family, usually one or more cases of diphtheria appeared shortly after the first cases, Namely :

In a family of three children all had the disease.

In a family of five curildren four had the disease.

In a family of three children two had the disease ; later in the year two members of this family had typhoid fever. In all cases the disease was strictly confined to the house where it first appeared, and in only one instance did the disease spread to other families living in the same teneiwent.

Of the twenty-seven cases four were young adults; the average age of the children was 5 years, the youngest being i 8 months.

As of importance in making an early differential diagnosis between diphtheria and follicular tonsilitis, I have found that in diphtheria :

I. The temperature was much lower, often normal.

2. The constitutional symptoms were usually less severe at first.

3. The glands about the neck were more swollen and tender.

In all cases $I$ have felt justified in making a diagnosis of diphtheria where there was membrane on the uvula or on the pillars of the pharynx.

As last year I could report that, having had in my charge in this district a large epidemic of scarlet fever, I was not aware of having carried the disease to a single child, so this year not a case of diphtheria has occurred in a family that was under my care for other diseases.

In other words, so far as an opinion can be formulated from so small a number of cases, the disease is very infections to young children brought in immediate contact with those sick; the disease does not spread from house to house; the disease is not easily carried by a third person.

The following list shows the character and distribution of the various infections diseases in the portion of the city above described, during like periods of two successive years.

JULY, I887, TO JANUARY, I888.

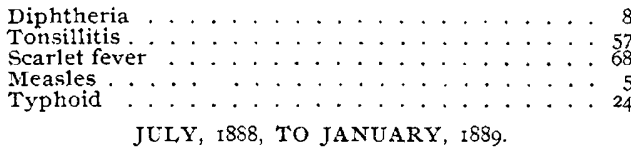

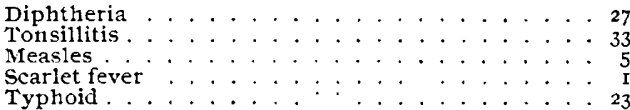

\section{MEDICAL PROGRESS.}

Nerve-Grafting.-At the meeting of the Clinical Society of London, on January 25, MR. MAyo RoBSON showed a girl, æet. 14, on whom he had successfully grafted two inches and a half of the posterior tibial nerve into a corresponding gap in the median nerve in the forearm. He also showed the tumor which had involved the median nerve, and had necessitated its removal. The history of the case, briefly, was that the patient had noticed the tumor growing for six years, but that it had grown more rapidly during the past twelve months, during which time it had 